\title{
Action and Protection Mechanisms of Free Radicals
}

\section{Monica Butnariu*}

Chemistry and Vegetal Biochemistry, Banat's University of Agricultural Sciences and Veterinary Medicine fromTimisoara, Romania

\section{Editorial}

Free radicals can initiate reversible, small-size changes not only due to the low intensity of their formation, but also to the dissipation and decomposition reactions. The factor determining the increase of the intensity of free radical formation is oxygen activation. Due to the presence of this element not only in the atmosphere but also in almost all the substances in the body, the interaction of free radicals with oxygen is inevitable. They attack the existing pro-oxidants (substances/ ions) for which the free radicals have an affinity. The action of free radicals on pro-oxidants is neutralised by the antioxidants or by the reactions of free radicals. The potential of the process of peroxidation consists in the exceeding pro-oxidant concentration and is superior numerically to the pro-oxidant concentration [1].

The postulate of the ageing theory is based on the reactions of free radicals involved in the changes caused by ageing. The changes are associated with the environment, with diseases, and with the intrinsic ageing process. This theory is based on the chemical nature of the reactions of free radicals and on their omnipresence.

The most reactive of all oxygen free radicals is hydroxyl, which reacts with deoxiribose and the bases of the DNA. As a result of the postulate of the ageing theory, we can draw two conclusions on the relationship between the deterioration of the DNA and maximum life span. The increase agents/processes of the rate of deterioration of the DNA and the decrease of DNA recovery can speed up the ageing process.

Thus, decreasing life span and apparent deterioration speed, we can decrease proportionally the speed of the specific metabolism (the energetic nutritional supplement) [2]. ROS are considered factors that cause cell de-differentiation since they react with chromatin, they change the bases of the DNA, and they cause ruptures of the chain; they induce chromosomal aberrations and a long life in the species with a low rate of accumulation of chromosomal aberrations; long life species have a low rate of accumulation of age pigments, lipofuscine, because ageing rate is proportional with metabolic rate for many different species.

The oxidative changes of proteins under the action of ROS can result in inactivation of membrane enzymes and proteins and can induce structural changes resulting in destabilisation of cell morphology when the target of the oxidative attack is cytoskeleton elements [3].

In the case of enzymes, the effect of ROS consists in a diminution of the catalytic capacity. The size of changes is determined by the relative location of the formation site of ROS, of antioxidant systems, and of target-protein [4]. ROS play a role in mitochondrial damage and in permanent senescence. The results of ageing show a decrease of the number of mitochondria and the fact that the organites in the aged cells undergo biochemical alterations. Mitochondrial DNA (mtDNA) can suffer a higher oxidative damage than nuclear DNA.

Ageing is caused by the damage of mtDNA and by the peroxidation of lipids by free radicals in the inner mitochondrial membrane. Rapidly replicated cells do not allow the attack by free radicals because they use low levels of oxygen. The mitochondrial of short-life span species generate larger amounts of ROS than long-life span species. mtDNA damage can block mitochondrial turnover and replication, with concomitant damage of the membrane (peroxidation processes). We can say that mitochondrion that consumes about $80-90 \%$ of the oxygen of a cell for the synthesis of the adenosine triphosphate (ATP) through oxidative phosphorilation serves as a target for ROS in aged tissues [5].

UVA radiations are little absorbed by nucleic acids since their maximum of absorption is $260 \mathrm{~nm}$. UVA radiations interact with the DNA through indirect mechanisms mediated by endogenous photosensitising compounds. The fact that the irradiation of the cells in the absence of oxygen diminishes the lethal effect of the UVA radiations shows the involvement of ROS in the interaction of UVA radiations with nucleic acids [6].

UVA induce lesions of the DNA through the splitting of phosphodiesteric bonds at the level of a single chain and the formation of crossed bonds neuraminidase-protein and dimerisation of adjacent pirimidines. Despite of the complexity of the ageing process, a few mechanisms influence strongly the ageing rate.

This concept forms the bases of longevity determining ageing hypotheses that could be stated as follows: differentiated cells represent the primary ageing process; ROS cause the differentiation; and active mechanisms stabilise the proper state of the differentiation, as well as antioxidants represent the category of longevity determinants. A target of the radicalic attack is membrane lipids, because of the double bonds in the structure of PUFA. The most frequent PUFA in the structure of membrane phospholipids are linoleic, linolenic, arachidonic acids. The process of peroxidation of PUFA consists in the following steps: a free radical extracts a hydrogen atom from the allylic position, with turning the PUFA into a lipid radical; then, there is intramolecular rearrangement of the double bonds with formation of a conjugated diene; as a result of the reaction between the conjugated diene and the molecular oxygen, there occurs a peroxyl radical which can react with another molecule of PUFA forming lipid radicals, with the turning of the peroxyl radical into lipid hyperoxide.

Alternatively, the peroxyl radical can form cyclic peroxides. Lipid peroxides, once formed, undergo splitting resulting in the propagation

*Corresponding author: Monica Butnariu, Chemistry and Vegetal Biochemistry, Banat's University of Agricultural Sciences and Veterinary Medicine from Timisoara 300645, Calea Aradului 119, Timis, Romania, Tel:+40-0-256-277-464; Fax:+40-0 256-200-296; E-mail: monicabutnariu@yahoo.com, monica_butnariu@usab-tm.ro

Received November 15, 2012; Accepted November 16, 2012; Published November 22, 2012

Citation: Butnariu M (2012) Action and Protection Mechanisms of Free Radicals. J Pharmacogenom Pharmacoproteomics 3: e129. doi:10.4172/21530645.1000e129

Copyright: (c) 2012 Butnariu M. This is an open-access article distributed under the terms of the Creative Commons Attribution License, which permits unrestricted use, distribution, and reproduction in any medium, provided the original author and source are credited. 
of the reaction chain and in ramification and decomposition reactions [7]. The decomposition of the lipid peroxides results in such compounds as alkanes (ethane, pentane), aldehydes (malonic dialdehyde, hexanal, 4 -hydroxinonenal), epoxy and hydroxy fatty acids. The peroxidation of membrane lipid affects the structure and functions of plasmatic and organite membranes. Thus, transmembrane potentials, ionic flows, and transmembrane transport are troubled, membrane receptors are inactivated, and signalling paths are deregulated. Through the process of lipid peroxidation, there occur membrane components change of lipid and protein nature as a result of the reaction of some amino acids with aldehyde peroxidation products [8]. Free radicals and oxidative stress plays a role in the decrease of dysfunctions at cell level and of the different diseases at body level. The balance between the oxidative actions of free radicals and the level of antioxidants in a body essential for life and characterises the capacity of resistance and adaptation of a living body. Organisms are protected by the aggression of ROS in several ways: cell compartmentation, protection by antioxidant compounds and by enzymatic systems, the organisms' capacity of developing inducible adaptive responses under conditions of oxidative stress [9].

Table 1 shows that enzymatic systems are more efficient in favouring and controlling peroxidation.

Defence systems consist in the synergic action at different levels of free radical formation; they focus, mainly, on the first radical and on

\begin{tabular}{|c|c|c|}
\hline No. & Pro-oxidants & Antioxidants \\
\hline 1 & Folic acid & Uric acid \\
\hline 2 & Adrenalin & Tiroxin \\
\hline 3 & Aromatic compounds & Flavonoid \\
\hline 4 & Metal ions Fe, Co & Vitamin C (ascorbic acid) \\
\hline 5 & Lipoxygenase & Glutation peroxidase \\
\hline 6 & Nitrile & Estrogens \\
\hline 7 & Synthesase prostaglandin & Vitamin $\mathrm{E}$ (tocopherol) \\
\hline 8 & Vitamin $\mathrm{B}_{6}$ (pyridoxine) & Iron chellators \\
\hline 9 & Vitamin $\mathrm{D}_{2}$ and $\mathrm{D}_{3}$ & Methionine \\
\hline
\end{tabular}

Table 1: Systems of pro-oxidants and antioxidants.

\begin{tabular}{|c|c|c|c|}
\hline Antioxidant & Antioxidant & Location & Type of action \\
\hline \multirow{5}{*}{ Proteins } & Ferritin & cytoplasm & chelation $\mathrm{Fe}^{2+}$ \\
\hline & Transferrin & extra cellular fluid & chelation $\mathrm{Fe}^{2+}$ \\
\hline & Lactoferrin & extra cellular fluid & chelation $\mathrm{Fe}^{2+}$ \\
\hline & Ceruloplasmin & extra cellular fluid & $\begin{array}{c}\text { chelation } \mathrm{Cu}^{2+} \text {, oxidation } \\
\mathrm{Fe}^{2+} \text {, scavenger } \mathrm{O}_{2}^{-}\end{array}$ \\
\hline & Albumin & extra cellular fluid & $\begin{array}{c}\text { chelation } \mathrm{Cu}^{2+}, \\
\text { scavenger } \mathrm{OH}^{\circ}, \mathrm{LOO}^{\circ} \text {, } \\
\mathrm{HOCl}\end{array}$ \\
\hline \multirow{7}{*}{$\begin{array}{l}\text { Compounds with } \\
\text { small molecular } \\
\text { mass }\end{array}$} & Vitamin $\mathrm{E}$ & membranes & $\begin{array}{c}\text { scavenger } \mathrm{OH}^{\circ}, \mathrm{LOO}^{\circ}, \\
\mathrm{HOCl}\end{array}$ \\
\hline & Ubiquinone & membranes & $\begin{array}{c}\text { scavenger } \mathrm{OH}^{\circ}, \mathrm{LOO}^{\circ}, \\
\mathrm{HOCl}\end{array}$ \\
\hline & Carotenes & membranes & $\begin{array}{c}\text { scavenger } \mathrm{OH}^{\circ}, \mathrm{LOO}^{\circ}, \\
\mathrm{HOCl},{ }^{1} \mathrm{O}_{2}\end{array}$ \\
\hline & Vitamin C & cytoplasm & scavenger $\mathrm{OH}^{\circ}, \mathrm{O}_{2}^{-}$ \\
\hline & $\begin{array}{l}\text { Reduced } \\
\text { glutation }\end{array}$ & $\begin{array}{l}\text { cytoplasm, } \\
\text { mitochondria }\end{array}$ & scavenger $\mathrm{OH}^{\circ}, \mathrm{O}_{2}^{-}$ \\
\hline & Uric acid & blood & $\begin{array}{l}\text { prevents lipid } \\
\text { peroxidation }\end{array}$ \\
\hline & Bilirubin & blood & $\begin{array}{l}\text { prevents lipid } \\
\text { peroxidation }\end{array}$ \\
\hline
\end{tabular}

Table 2: Main antioxidant compounds, location and mechanism.

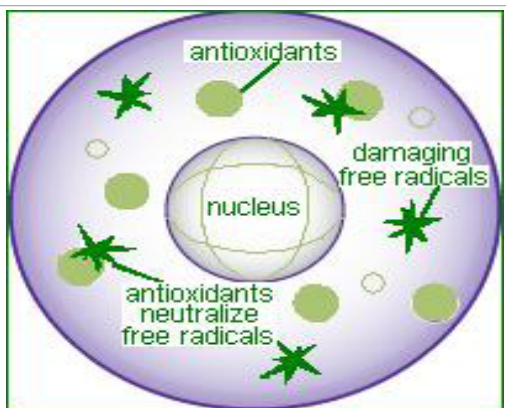

Figure 1: Antioxidants neutralise free radicals normally produced by cell metabolism

the last peroxide; they are localised in and outside the cell; the systems of antioxidants are coupled with the main metabolic reactions in the cell; SOD and CAT have a higher speed of reaction; they have a double action-pro-oxidants and anti-oxidants; and they lack specificity. Table 2 presents the main antioxidant compounds and their mechanisms.

Such substances as ascorbic acid or compounds containing hem (haemoglobin, myoglobin) can act as pro-oxidants (in low concentrations) or as antioxidants [10].

Free radicals attack the antioxidants producing other specific free radicals (tocoferil, thiol) with low reactivity, which participate less in the reactions of initiation of peroxidation [11]. Antioxidant compounds are classified after their type of action into scavengers and "preventive" antioxidants:

- scavengers are compounds that prevent oxidative stress by capturing free radicals;

- "Preventive" antioxidants are compounds that act by sequestrating the ions of transition metals, preventing the Fenton reaction.

The processes of recovery and turnover help minimising the lesions caused by the attack by ROS.

Under normal conditions, there is balance between antioxidant systems and systems generating ROS. Troubling this balance in favour of pro-oxidative systems determines oxidative stress, with pathological implications [12]. The enzymatic protection system covers: SOD, CAT, GPx, GST, GR and glucozo-6-phosphate dehydrogenase. Enzymes have a mainly intracellular location the extracellular environment being exposed much more to radicalic attack [13]. Complex biomolecules such as those in the structure of organisms root their stability in the parity of molecule electrons (Figure 1).

When a molecule looses an electron, it becomes unbalanced from an electrochemically point of view, unstable biochemically and reactive, trying to recover its stability through the violent capture of an electron from another molecule. Each time a free radical attacks a normal molecule to capture one of its electrons; the molecule changes its initial properties, turning, in its turn, into a free radical [14]. A cell mutilated in this way al molecular level loses its basic functions turning into a source of free radicals ready to attack other cells and changing their functions. Thus, an uncontrolled chain of biochemical reactions damaging the organism is generated, with very serious repercussions in time. 
Citation: Butnariu M (2012) Action and Protection Mechanisms of Free Radicals. J Pharmacogenom Pharmacoproteomics 3: e129. doi:10.4172/2153$0645.1000 \mathrm{e} 129$

Page 3 of 3

\section{References}

1. Ranaldi G, Bellovino D, Palozza P, Gaetani S (2007) Beneficial or detrimental effects of carotenoids contained in food: cell culture models. Mini Rev Med Chem 7: 1120-1128.

2. Sanders LH, Devadoss B, Raja GV, O’Connor J, Su S, et al. (2011) Epistatic roles for Pseudomonas aeruginosa MutS and DinB (DNA Pol IV) in coping with reactive oxygen species-induced DNA damage. PLoS One 18: e18824.

3. Galloway E, Shin T, Huber N Eismann T, Kuboki S, et al. (2008) Activation of hepatocytes by extracellular heat shock protein 72. Am J Physiol Cell Physiol 295: C514-C520.

4. Xiong Y, Uys JD, Tew KD, Townsend DM (2011) S-glutathionylation: from molecular mechanisms to health outcomes. Antioxid Redox Signal 15: 233-70.

5. Takabe W, Li R, Ai L, Yu F, Berliner JA, et al. (2010) Oxidized Low-Density Lipoprotein-Activated c-Jun $\mathrm{NH}_{2}$-Terminal Kinase Regulates Manganese Superoxide Dismutase Ubiquitination. Implication for Mitochondrial Redox Status and Apoptosis. Arterioscler Thromb Vasc Biol 30: 436-441.

6. Reelfs O, Macpherson P, Ren X, Xu YZ, Karran P, et al. (2011) Identification of potentially cytotoxic lesions induced by UVA photoactivation of DNA 4thiothymidine in human cells. Nucleic Acids Res 39: 9620-32.

7. Zuniga KE, Erdman JW Jr (2011) Combined consumption of soy germ and tomato powders results in altered isoflavone and carotenoid bioavailability in rats. J Agric Food Chem 59: 5335-5341.
8. Morris CR, Gladwin MT, Kato GJ (2008) Nitric oxide and arginine dysregulation: a novel pathway to pulmonary hypertension in hemolytic disorders. Curr Mol Med 8: 620-32.

9. Dang H, Yang L, Wang S, Fang F, Xu F (2012) Calcitonin gene-related peptide ameliorates hyperoxia-induced lung injury in neonatal rats. Tohoku J Exp Med 227: $129-138$.

10. Mano J (2012) Reactive carbonyl species: their production from lipid peroxides action in environmental stress, and the detoxification mechanism. Plant Physio Biochem 59: 90-97.

11. Kanamoto T, Rimayanti U, HO, Kiuchi Y (2011) Platelet-derived growth factor receptor alpha is associated with oxidative stress-induced retinal cell death Curr Eye Res 36: 336-340.

12. Kaynar H, Meral M, Turhan H, Keles M, Celik G (2005) Glutathione peroxidase, glutathione-S-transferase, catalase, xanthine oxidase, $\mathrm{Cu}-\mathrm{Zn}$ superoxide dismutase activities, total glutathione, nitric oxide, and malondialdehyde levels in erythrocytes of patients with small cell and non-small cell lung cancer. Cancer Lett 227: 133-139.

13. Jomova K, Vondrakova D, Lawson M, Valko M (2010) Metals, oxidative stress and neurodegenerative disorders. Mol Cell Biochem 345: 91-104.

14. Jiang J, Arp J, Kubelik D, Zassoko R, Liu W (2007) Induction of indefinite cardiac allograft survival correlates with Toll-like receptor 2 and 4 downregulation after serine protease inhibitor-1 (Serp-1) treatment. Transplantation 84: 1158-1167. 